\title{
Organizational Business Interest as Organizational Request
}

By

Dr. Nasser Fegh-hi Farahmand ${ }^{1}$

\begin{abstract}
Making a difference in organization or creating the very best product or service on the market or simply doing something loves to do. Furthermore, it seems that the emphasis on organizational empowerment as structure, and systems has not yielded the desired results as some of the companies where these variables have been changed, after sometime, went back to experiencing declining performance. It is therefore obvious that more research needs to be done to identify characteristics that enhance organizational performance. Implementing good environmental and organizational practices is good organizational business it can give a competitive advantage. This article attempts to explain the organizational business interest by patterns of thinking. Organizations use organizational resources as the basic ingredient for all that is required for their operations. They are therefore eager to maintain and improve the quantity of expendable organizational resources by not only resources utilization, but by also identifying, nurturing and maintaining characteristics that promote organizational performance. The key to organization success is having a organizational business interest in place. Whether organization is about to launch a start-up or organization have been in organizational business for years, organizational business' direction is guided by your organizational business interest. In spite of this general awareness, such long-term organizational business, strategic-level interest of organizational business has been lacking in most organizations.
\end{abstract}

Key words: organizational business interest, organizational business interest, organizational request

\section{Introduction}

Most likely, organization will quantify success in many ways. It isn't difficult to envision what you want out of organizational business, but how will organization get there? There are many common steps you can take and missteps you should

| ${ }^{1}$ Department of Industrial Management, Tabriz Branch, Islamic Azad University, Tabriz, Iran E-mail: farahmand@iaut.ac.ir 
avoid on organization pathway to prosperity. Improved and sustainable performance ensures that an organization continues to fulfill its mission and survive into the competitive future. The fact that some variables affect organizational empowerment managers and some researchers to seek to identify those factors that positively or negatively affect the particular organization or industry of their interest with the aim of strengthening the positive variables and ameliorating the effect of the negative ones for those organizations and industries to post superior economic performance. The importance of strategic, long-term policy and organizational business interest is very clear to interests. Many externals and organizational variables have been identified in the literature as affecting organizational empowerment. Organizational business managers like to follow a similar and routine organizational business behavioral pattern. Organizational business interest, normally taken as a part of organizational business interest, therefore also tends to run in cycles of around last years. A central motivation for this has been the public uneasiness towards many of the applications of gene organizations technology, as well as the general distrust of the public towards officials, scientists and representatives of organizations in the management of risks. Organizations are most likely to do the same when experiencing decline. Without organizational empowerment, management cannot enable an organization to compete for the future, but developing distinctive capacity can. One then wonders if developing appropriate characteristics in conjunction with appropriate competencies would not ensure a better performance in a more intensely competitive future. It is generally arguing that effective organizational business interest is one of the important factors in organizational business success. The most extensive review, although now some years old, is the analysis that there seemed to be a consensus that interest was linked positively to growth undertaken.

\section{Organizational business interest}

The operational concept based on customer satisfaction where the operation of quality management system is customer-oriented and aims at improving customer satisfaction; customers' needs and expectations are satisfied through clear management request, communication, resource management and product realization process; the structure of measuring and monitoring customer satisfaction proposed on the basis of overall performance of the quality system and requires enterprises evaluate performance from the perspective of customers. In organization, where a organizational business interest exists, the preparation of the organizational business interest may driven by external forces. The most obvious of these are the requirements of external agencies providing funding for 
either start up or expansion. There are some argues that formal written interest may be inappropriate for the organizations but this seems a minority view. It can be argued that organizational business interest is as important to organizations as to larger organizations and standard textbooks on entrepreneurship offer chapters on organizational business interest whilst a range of specialist publications outline the best ways of writing organizational business interest. In addition to its role in organizational business funding, the organizational business interest may serve as a strategic interest document for the entrepreneurs, a interest to guide the organizational business and serve as a basis for taking strategic decisions and it may serve as a subsequent monitoring device. Anyhow, organizational business interest gives an overview of organizational business where organizations have been, where you are now, and where organization is going in the future. The more we understand people and their total environment, the more their needs are likely to be met. When we talk about valuing workers relationships, the scope of definition is expansive. On the one hand, it is simply the value that workers generate for the organization. On the other hand, it is purely the value of the relationship. Neither definition is more correct than the other; however, the purpose and for valuing each are different. A positive experience throughout the workers cycle should foster trust and develop loyalty, therefore allowing an organization to generate more revenue for less incremental expenditure. However, the escalating cost of scientific and technological research and development, together with the limiting resources of governments, make such of overall support impossible, even for relatively rich countries. The organizational performance information, unclear goals, inappropriate selection and use of technology, inability to integrate workers and processes and use of misleading metrics or improper measurement tendencies are the major barriers in implementing and managing projects systems that seek to identify individuals with the ability to learn and adapt to new situations and markets can provide a firm with competitive advantage.

\section{Organizational business interest factors}

The importance of strategic, long-term policy and interest in science and technology is very clear to interests and policy developers, from the fact that they need both considerable resources in order to carry out the interest activities, and a long lead time to accumulate the required trained manpower. The starting point in the organizational business interest is the assumption of organizational business. The central mission of organizations activities under the enlightenment model is to raise the organizational business interest level of the organization. To begin the interest process, organization will need to do some critical analysis; organizational business interest is about realistically forecasting where organizational business is 
going. A few tactical actions for implementation can make the challenge simpler and provide leadership that is supporting. Obtain support from the board of directors, because an organization's total quality efforts must begin at the very top and begin with the board of directors. There was every reason to believe that the organizational worker could be as efficient and productive as its counterparts anywhere in the world. The performance of organization, which determines its business and growth, depends to a large extent on the productivity of its Organizational business interest. In fact, the wealth of a nation as well as socioeconomic well being of organization depends on the effectiveness and efficiency as productivity of its various sub components. Productivity should reflect our total commitment to improve the way we do things, our attitude to work, a commitment to improve our work ethics, a commitment that whatever we do today can be improved upon. Tackling and overcoming the problem of low productivity of organizational workers is not impossible although daunting. It is not enough for us to understand the socio-cultural sources of these deviant orientations, it is necessary for us to do something practically to arrest and control them. Organizational business interest is generally regarded as the most dynamic of all the factors that are employed for the creation of wealth, having the potential to energies and serve as catalyst to all of the other resources. Productivity is thus of fundamental importance to the Organizational business interest of whatever status, to the organization whether commercial or not and to the national economy at large and accordingly. However, the significance of the influence of the environment on organization's operational activities and performance was only acknowledged. In fact, stress that organizational activities are influenced by what happens in the external environment. Inability to ineffectively manage the human factor as manifested in several negative ways including the following; employees often arrive at the office fatigue and exhausted as a result of poor transportation facilities and harsh living conditions in most urban cities. They are also compelled to make use of materials and machinery which are far from suitable for attaining the desired level of performance. Performance by productivity in an organization can, in principle, be influenced by a wide range of internal and external variables, which may be categorized. To begin with, a significant number of organizational business people, as also organizational business engineering, would be selected for this support to make an impact. Flexible mechanisms for induction of new strengthening of science organizational business engineering in key areas of science would be developed. Performance by productivity, the problem remained more or less unabated. It is not in doubt that organization is richly and extra-ordinarily endowed with all the three basic principal factors needed for enhancement of productivity, namely, capital and 
resources, it has been unable to take advantage of these factors to obtain at least a corresponding level of outputs consequent to which the country, several years since it attained political independence, is yet poverty ridden. This process would naturally entail reversing the present flow of organizational business talent away from science organizational business technology by innovative schemes. In order to encourage world class organizational business in science organizational business technology, mobility of science organizational business technology between organization and organizational environment will be ensured. For building up the personnel of organizational business engineering base in relevant areas, the agencies and departments concerned with science organizational business technology will make available substantial funding from their allocation. Flexible organizational business mechanisms will be put in place in organization and organizational environment to enable organizational business researchers to change fields and bring new inputs into traditional disciplines, and also to develop world class organizational business areas. There will be emphasis on a continuing process of retraining and re skill to keep personnel of organizational business engineering with the rapid advances taking place. Wherever considered necessary, training abroad will be resorted to, so as to build up a skilled base rapidly. New mechanisms would be instituted to facilitate the return of personnel of organizational business engineering and organizational business technologists of organization as also their networking, to contribute to organizational environment and science organizational business technology. It will also be ensured that higher education is available to the widest possible section of creative personnel of organizational business engineering. Priority will be placed on the development of science organizational business technology which address the basic needs of the population; make organizational competitive and make the economically organizational business strong. Special emphasis will be placed on equity in development, so that the benefits of science organizational business technology growth reach the majority of the population, particularly the disadvantaged sections, leading to an improved quality of life for every citizen of the organization. These aspects require science organizational business technology foresight, which involves not only forecasting and assessment of technologies but also their organization and organizational environment environmental consequences. Intensive of science organizational business engineering will be launched to develop innovative science organizational business technology of a breakthrough nature; and to increase our share of high-tech products. Aggressive international benchmarking will be carried out. Simultaneously, efforts will be made to strengthen traditional industry so as to meet the new requirements of competition through the use of appropriate science organizational business 
technology. This organization is particularly important as it provides employment at lower per capita investment, involves low energy inputs, and carries with it unique civilization traditions and culture. Value addition and creation of wealth through reassessment, redistribution and repositioning of our intellectual, capital and material resource will be achieved through effective use of science organizational business technology. Quality standards of science organizational business engineering, testing and calibration laboratories according to international requirements will be given an enhanced push to enable world class organizational business to avoid non-tariff barriers in global trade. Innovation will be supported in all its aspects. A comprehensive innovation of science organizational business engineering system will be created covering science organizational business technology as also legal, financial and other related aspects. There is need to change the ways in which organizational business performs, if innovation has to fructify. Every effort will be made to achieve synergy between research of science organizational business engineering and scientific research. Autonomous technology transfer organizations will be created as associate organizations of universities and national laboratories to facilitate transfer of the know-how generated to organization. Increased encouragement will be given, and flexible mechanisms will be evolved to help, science organizational business technology to transfer the know-how generated by them to the industry and be a partner in receiving the financial returns. Organization will be encouraged to financially adopt or support educational and research institutions, fund courses of interest to them, create professional chairs etc. to help direct organization towards tangible organizational goals. Indigenous knowledge would be further developed and harnessed for the purpose of organizational business generation. Development of science organizational business technology adds value to organizational resources and which provide holistic and optimal solutions. Management of science organizational business engineering: science organizational business technology has an important role in any general to address the problems of management of the impacts of natural hazards. A concerted action interest to organizational business enhances predictive capabilities and preparedness for meeting emergencies will be drawn up. Measures will be undertaken to promote research on natural phenomena that lead to management of science organizational business engineering activities that aggravate them. This will be with a view to developing practical science organizational business technology solutions for management of science organizational business engineering. 


\section{Organizational business interest implementation}

There is growing need to enhance public awareness of the importance of science organizational business technology in everyday life, and the directions where science organizational business technology is taking us. Organization must be able to consider the implications of emerging science organizational business technology options in world class organizational business areas. A closer interaction of those involved in the science organizational business technology, management of science organizational business engineering: science, knowledge of science organizational business engineering and other will be facilitated to bring about mutual reinforcement, added value and impact. Technology cooperation of science organizational business engineering as science organizational business technology development can benefit greatly by world class organizational business cooperation and collaboration. Common goals can be effectively addressed by pooling both material and intellectual resources. World class organizational business programs will be encouraged between organizations. Keeping in view these broad objectives, it is essential to spell out a organizational business interest implementation that will enable identification of specific interests, programs and projects, with clearly defined tasks, estimates of necessary resources, and time targets. Special emphasis will be placed on collaborations with other developing organizations and technology cooperation of science organizational business engineering would be fully used to world class organizational business interests as an important component of policy initiatives. Monitoring of science organizational business engineering for effective monitoring of science organizational business engineering and reviewing mechanisms will be significantly strengthened, and wherever not available will be put in place. It will be ensured that the scientific community is involved in, and responsible for, smooth and speedy implementation. Outline how organization wants to market and or sell product online. This can be as simple as developing a basic brochure style website to provide information about product or service. It can be as complex as a comprehensive marketing that includes a well-optimized, ecommerce website with an online advertising campaign including banner and affiliate advertising. When organization looks at organizational product or service, it should consider how suited it is to marketing. Suitable mechanism will be evolved by which independent inputs on science organizational business technology and interesting are obtained on a continuous basis from a wide cross section of science organizational business technology. It will utilize the academies and specialized professional bodies for this purpose. These inputs will form an integral part of the organizational business interesting and implementation of all programs relating to science organizational business technology, as also in 
government decision making and formulation of policies in organizational business sectors. A greater integration of the programs in organizational business sectors with science organizational business technology activities will go a long way in ensuring a wider, more visible and tangible impact. This will call for a certain percentage of the overall allocation of each of the science organizational business technology to be devoted for relevant programs and activities in organizational business technology. A concerted organizational business interest is necessary to infuse a new sense of dynamism in our science organizational business technology. The science organizational business technology departments, agencies and other academic institutions, including universities i.e. the science and science organizational business technology system as a whole, would be substantially strengthened, given full autonomy and flexibility, and debureaucratized. Organization will ensure continued existence of a organizational business interest which will assist in formulating and implementing various programs and policies. It will have appropriate representation of organization leaders, leading science organizational business technology and various scientific departments. Organization will make necessary budgetary commitments for higher education and science organizational business technology. It will, through its own resources and also through contribution by organization, raise the level of investment on science organizational business technology by the end of the interest. For this, it is essential for organization to steeply increase its investments in organizational business interest. Organization should discuss ways in which organizational business honors ethical values and respects people, organizational community, and the environment. Organization may even choose to use webbased organizational business interest applications or purchase software to help organization prepare organizational interests and forecasts. Listed below are a number of organizations that offer free templates and sample interests.

\section{Organizational business interest as organizational request}

An excellent place to start organizational search for good examples of organizational business interests or templates is the organizational business office in organization region. Organizational business information officers are able to provide you with access to materials that can be tailored to organizational needs; all it takes is a visit in person, a phone call or an email. Organizational local organizational business centre offers a wealth of information, including practical tools and guides and specific examples, on how to start the interest process. There are many other organizations and organizational business websites that provide free templates, writing guides and sample interests. Implementing good environmental and organizational practices is good organizational business can 
give organization a competitive advantage and help foster goodwill toward organizational business. Customer satisfaction and target management structure derive management system requirements. Organizational business interest turn customer input into innovation how organization find out the organizational business opportunities in most new products and services and how to rank these opportunities in a prior sequence? However, the outcome-oriented customers study provides a simply and definite answer, which is that the best organizational business opportunity is in the customer recognized important items, where existing products can not meet their needs. A Web host will provide space for organizational website and allow it to be viewed online. Organization is essentially renting space on the Internet, so it can put organizational website there much like you might rent an office. Organization should set up definite policy and target and also the degree of customer satisfaction should be clarified. According to quality target, enterprises should interest total management system structure, authority and request control, operation process, in order to ensure comply with interest and achieve enterprise quality target. Organization should carry out communicating harmonization, encourage staffs involvement and full commitment to customer satisfaction, also managers' decision-making should comply with the organizational business policy and target as the maximum guidance principle. Organizations provide all required resources, according to the interest then produce and sell products to customers. After the adjustment and improvement, enterprises should re-measure customer satisfaction, to ensure the improvement scheme is proper and effective. Organization should provide customers' feedback information to management for inspection and verify appropriateness and effectiveness of the definition of quality policy and target, quality scheme and operation methods. Relevant certifications, such as fair-trade certification, organic certification, or leadership in energy and environmental design certification. Environmental programs and resources could impact organizational business, from greening your organizational business to finding funding to become environmentally efficient. In order to stay competitive in today's market, organization might want to consider where corporate organizational request fits into your operations. The difficulty in long-term organizational business interest is also due to the rapid and unpredictable evolution of science organizational business, making it very hazardous to forecast development beyond a period. Organizational business interest in organizations acquired an impetus with long-term policy statements, such as organizational business vision. While larger organization is often very good at providing Internet access, it do not always offer the same level of personalized customer service and specialization as a mid-sized organization. This calculation provides 
the organizational business opportunity; therefore organization is able to identify the best organizational business opportunity with the most potential. Although this study provides an advanced positive view point-outcome-oriented customers study, in practice, it will be difficult to examine because of products receivers, users' difference, even some products are only provided for urgent use and the after-use result and performance can not be obtained. Effectively using information technology is an important part of managing a organizational business. In e-organizational business interest, organization should outline how organization interests to use internet technologies to reach customers, manage organizational business, and reduce costs. Organization should include information. A science organizational business vision provides the wanted scenario to strive for, the end point of a long-term policy. However, the organizational business vision must be accompanied by a roadmap to allow the journey which starts now, to reach the required destination in the future. Steps will be taken to network the existing infrastructure, investments and intellectual strengths, wherever they exist, to achieve effective and optimal utilization, and constantly upgrade them to meet changing needs. Keep in mind that implementing e-organizational business strategies can save money if this is the case for organization may want to highlight potential savings in this section. Organization must look at what organizational want to get out of e-organizational business and the different ways for making that happen.

\section{Conclusion}

Clear guiding ideas and principles concerning quality and organizational business as well as acomprehensive, company-wide realization model for organizing the ideas are not enough for getting quality happen. Practical means, tools, methods, etc., especially relevant management methodology, are available to get the concrete in practice. For this purpose, a collection of management tools hascreated at organizations. Some of these tools have created and maintained by organizationalbusiness experts. Corporate sustained growth relies on the ability to continually generate profits; this in turn depends on their products meeting customers' needs and expectations. Generally, customer satisfaction is evidenced in the high rate of customer loyalty, good reputation, increase in market share, improvement of performance and reduction in complaints, etc. In contrast, the results of poor customer satisfaction include loss of customers, decrease in market share, deterioration of performance, poor reputation and increase in customer complaints, etc., which directly affects gross turnover and operating costs. Therefore, customer satisfaction has become an important operating goal to which enterprises have competed to make the commitment. Moreover, measuring 
and monitoring customer satisfaction has become an important research topic for enterprises. Systematically monitoring customer satisfaction can provide managers with useful information for diagnosis, help an enterprise identify areas of improvement and thus increase business through continuous improvement in customer satisfaction. This study attempted to explain how to set up a complete customer satisfaction and target management system based on the concepts of customer satisfaction and target management proposed in organizational business and e-organizational business interest as organizational request conduct real-world case study, identify the critical items in customer recognition through market analysis, survey of satisfaction and organizational business opportunity algorithm and eventually integrate corporate objectives to achieve sustained improvement.

\section{References}

Feghhi Farahmand, Nasser (2001), Executive Management Process, Islamic Azad University, Tabriz Branch, Iran, pp 109-203.

Feghhi Farahmand, Nasser (2003), Permanent Management of Organization, First edition, Frouzesh Publication, Tabriz, Iran, pp15-32.

Feghhi Farahmand, Nasser (2003), Strategic Structure of Organization Management Process, Forth edition, Islamic Azad University, Tabriz Branch, Iran, pp 110-125.

Feghhi Farahmand, Nasser (2005), Strategic Management of Organization, First edition, Frouzesh Publication, Tabriz, Iran, pp 19.

Feghhi Farahmand, Nasser (2009), Organization Strategic Interest compilation, First edition, Frouzesh Publication, Tabriz, Iran, pp 131-134.

Feghhi farahmand, Nasser (2011), Active and Dynamic Management of Organization, Second edition, Frouzesh Publication, Tabriz, Iran, pp 112-120. Feghhi Farahmand, Nasser (2011a), Technology Management of Organization, Second edition, Frouzesh Publication, Tabriz, Iran, pp 201-205. FIB (1998). Uusinta tietoa suomalaisten asenteista biotekniikkaan, FIB, Suomen Bioteollisuus.

Frewer, L.,Rowe, G.,Marsh, R. and Reynolds, C. (2001). Public Participation Methods: Evolving and Operationalising an Evaluation Framework. UK Department of Health.

Fuller, S. (2000). The Governance of Science: Ideology and the Future of the Open Society. Buckingham - Philadelphia, Open University Press.

Hamel, G. and C. K. Prahalad, (1994). Competing for the Future. Harvard Organizational businessSchool, Boston, London.

Leonard, D., (1997). Spark innovation through empathic design. Harvard Organizational businessRev., 75: 102-113. 
Porter, M.E., (1985). Competitive Advantage. 1st Edn., Free Press, New York.

Robert, K. and N. David, (1992). The balanced scorecar measures that drive performance. Harvard Organizational business Rev., 70: 71-79. Stalk, G., (1988).

Time the next source of competitive advantage. Harvard Bus. Rev., 66: 41-51.

Ulwick, A.W., (2002). Turn customer input into innovation. Harvard Organizational business Rev.,

80: 91-97. http://www.canadaorganizational

business.ca/eng/125/141/http://www.canadaorganizational

business.ca/eng/145/146/http://www.canadaorganizational

business.ca/eng/87/187/

Irwin, A. (1995). Citizen Science. A Study of People, Expertise and Sustainable Development. London and New York, Routledge.

Irwin, A. and Wynne, B. (1996). Introduction. Misunderstanding Science? The PublicReconstruction of Science and Technology. Cambridge, Cambridge University Press: $1-17$.

Irwin, A. and Wynne, B., Eds. (1996). Misunderstanding Science? The Public Reconstruction ofScience and Technology. Cambridge, Cambridge University Press. Joss, S. and Durant, J., Eds. (1995). Public Participation in Science -The Role of ConsensusConferences in Europe. London, Science Museum with the Support of the European CommissionsDirectorate General XII.

Klüver, L.,Nentwich, M.,Peissl, W.,Torgersen, H.,Gloede, F.,Hennen, L.,Eijndhoven, J. v.,Est, R. v.,Joss, S. and Bellucci, S. (2000).. European Participatory Technology Assessment. Participatory Methods in Technology Assessment and Technology Decision-Making. Copenhagen, The Danish Board of Technology.

Kuwahara, T., (1997). Technology Foresight in Japan: a New in Methodology and Analysis. Technology Foresight, NSTDA, Bangkok, p. 87-93. 